\title{
IS BEING IN SCHOOL BETTER? THE IMPACT OF SCHOOL ON CHILDREN'S BMI WHEN STARTING AGE IS ENDOGENOUS
}

\author{
Patricia M. Anderson \\ Kristin F. Butcher \\ Elizabeth U. Cascio \\ Diane Whitmore Schanzenbach \\ Working Paper 16673 \\ http://www.nber.org/papers/w16673
NATIONAL BUREAU OF ECONOMIC RESEARCH
1050 Massachusetts Avenue
Cambridge, MA 02138
January 2011

Financial support from the USDA through the RIDGE Grant Program and the Robert Wood Johnson Foundation's Healthy Eating Research Program (Award \#57922) is gratefully acknowledged. We also thank Kosali Simon, Tom DeLeire and seminar participants at Indiana University for helpful comments. The views expressed herein are those of the authors and do not necessarily reflect the views of the National Bureau of Economic Research.

NBER working papers are circulated for discussion and comment purposes. They have not been peerreviewed or been subject to the review by the NBER Board of Directors that accompanies official NBER publications.

(C) 2011 by Patricia M. Anderson, Kristin F. Butcher, Elizabeth U. Cascio, and Diane Whitmore Schanzenbach. All rights reserved. Short sections of text, not to exceed two paragraphs, may be quoted without explicit permission provided that full credit, including (C) notice, is given to the source. 
Is Being in School Better? The Impact of School on Children's BMI When Starting Age is Endogenous

Patricia M. Anderson, Kristin F. Butcher, Elizabeth U. Cascio, and Diane Whitmore Schanzenbach NBER Working Paper No. 16673

January 2011

JEL No. I12,I21

\begin{abstract}
In this paper, we investigate the impact of attending school on body weight and obesity. We use school starting age cutoff dates to compare weight outcomes for similar age children with different years of school exposure. As is the case with academic outcomes, school exposure is related to unobserved determinants of weight outcomes because some families choose to have their child start school late (or early). If one does not account for this endogeneity, it appears that an additional year of school exposure results in a greater BMI and a higher probability of being overweight or obese. When actual exposure is instrumented with expected exposure based on school starting dates and birthday, the significant positive effects disappear, and most point estimates become negative and insignificant. However, for children not eating the school lunch, there is a significant negative effect on the probability of being overweight.
\end{abstract}

Patricia M. Anderson

Department of Economics

Dartmouth College

6106 Rockefeller

Hanover, NH 03755-3514

and NBER

patricia.m.anderson@dartmouth.edu

Kristin F. Butcher

Department of Economics

Wellesley College

106 Central Street

Wellesley, MA 02481

and NBER

kbutcher@wellesley.edu
Elizabeth U. Cascio

Department of Economics

Dartmouth College

6106 Rockefeller Hall

Hanover, NH 03755

and NBER

elizabeth.u.cascio@dartmouth.edu

Diane Whitmore Schanzenbach

School of Education and Social Policy

Northwestern University

Annenberg Hall, Room 205

2120 Campus Drive

Evanston, IL 60208

and NBER

dws@ northwestern.edu 


\section{Introduction}

In recent decades, there has been a stark increase in childhood obesity, with rates tripling from $5 \%$ in the early 1970 s to $15 \%$ by the early 2000 s. This increase in childhood obesity raises many concerns. For example, Type II diabetes is occurring at younger ages. In fact, we can no longer refer to juvenile diabetes and adult-onset diabetes, but instead use the terms Type I and Type II. In addition to health concerns, overweight children have been found to have lower quality-of-life scores, and there is some evidence that they may have worse academic outcomes (see Taras and Potts-Datema (2005) for a review of this literature). These concerns about childhood obesity have led to many studies, but to this point there is no "smoking gun" that clearly explains a majority of the increase. Given that children spend a large amount of time in school, many studies have focused on the school environment.

For example, Schanzenbach (2009) concludes that regularly eating school lunch (as opposed to bringing a lunch from home) increases obesity rates by about 2 percentage points. Similarly, Anderson and Butcher (2006) find that a 10 percentage point increase in the likelihood of being exposed to junk food in school results in a 1 percent increase in the average student's BMI. While these studies are consistent with school attendance being deleterious for one's health, it is important to realize that they do not necessarily imply that this is the case. Rather, they both indicate that some school environments are worse than others - that is, schools with higher quality lunches and less junk food would produce leaner children than those with lower quality lunches and more junk food. It may still be the case, though, that being in school is better than being out of school. Von Hippel et al. (2007) try to directly address this question, by comparing weight gain in the summer to weight gain during the school year. They conclude that 
the rate of weight gain is faster during the summer, although there are many caveats to their findings, including issues of seasonality.

A straightforward way to think about the impact of being in school versus not being in school takes advantage of school starting age cutoffs, an approach that has previously been used to estimate the effect of educational attainment on test scores (Gormley and Gayer, 2005; Cascio and Lewis, 2006), adult well-being (Dobkin and Ferreira, 2010), and birth outcomes (McCrary and Royer, forthcoming). Consider a state that requires that a child reach age 5 by September 1 in order to start kindergarten that fall. A child born on August 31 will start kindergarten at the age of five years and one day and be in school for the next year, while one born on September 2 will have to wait until the following year to begin kindergarten and will be aged 5 years and 364 days on entry. The only difference between these similar-age children is being born one day before or after September 1. Ideally, we would want to compare these children at the end of the year where one is in school and the other is not. However, since the slightly older child will always have one additional year of school exposure for a given age, later comparisons should also be informative. Much later comparisons, however, may begin to conflate any positive effect of education on health with a pure school exposure effect. ${ }^{1}$ Zhang (2007) uses school starting age laws in combination with the NLSY97 to determine that teenage girls with more education are less likely to be overweight, a finding she attributes to the possibility that education promotes healthier eating habits.

In this study, we estimate the reduced-form impact of being in school on children's body weight. We start by using data from the Early Childhood Longitudinal Study - Kindergarten cohort of 1998 (ECLS-K) to compare the weights of children who have one versus two years of school exposure. We first show that a simple ordinary least squares (OLS) approach is

\footnotetext{
${ }^{1}$ See Cutler and Lleras-Muney (2010) for a recent discussion of the education gradient in health.
} 
misleading. We then move to an instrumental variables approach that exploits the regression discontinuity in school exposure in birthday around school entry cutoff dates, described above. Using this approach, we find no strong evidence that an additional year of schooling has either positive or negative effects on weight outcomes, although there are some indications that school may be beneficial if one avoids eating the school lunch. We then supplement the ECLS-K results with some estimates using the National Longitudinal Survey of Youth Mother-Child matched data (NLSY79).

\section{Empirical Approach}

The fact that most states set a date by which children should be five years old in order to start kindergarten implies that some six year olds will be in first grade, while others will be in kindergarten. Consider, for example, a state with a September 1 cutoff. A child born on September 2 will miss the cutoff and be six at the beginning of kindergarten the following year (an “older starter"). By comparison, a child born just a day earlier who was allowed to start kindergarten (a "younger starter") will be in first grade when she is six. Thus, we have two children with almost identical ages, one of whom (the younger starter) has been exposed to school for an additional year. If, in fact, being in school improves weight outcomes, as implied by von Hippel et al. (2007) and Zhang (2007), then the younger starters should have a healthier weight for their age than the older starters. If, instead, the younger starters have a less healthy weight for their age than the older starters, then we can conclude that not only are some school environments worse than others (as in Anderson and Butcher (2006) and Schanzenbach (2009)), but that any school can be bad for weight outcomes. 
If everyone complied with the school starting age dates set by the states, a simple regression of weight outcomes on current grade, controlling for age, would replicate the thought experiment described above. One would indeed be comparing the six year old born September 2 and now in kindergarten with the six year old born August 31 and now in first grade. However, many schools do not strictly enforce the state cutoffs, and will allow the September 2 child to go ahead and start if the family requests it. More importantly, the entry cutoffs, even if strictly enforced, are only eligibility cutoffs in many states. Thus, while a child turning age five on August 31 is eligible to start kindergarten, there may be no requirement that he start. Typically, school attendance requirements only apply to an older age (as part of truancy laws). For example, a state with a September 1 cutoff makes a child who is five on September 1 eligible for kindergarten, but the child may not be required to be in school until they are six (or even seven if the state does not require kindergarten) on September $1 .^{2}$ As a result, actual grade is determined not just by the state legislation, but also by parents' decisions.

Over the past several decades, the trend has been to send children to kindergarten at older ages. ${ }^{3}$ Deming and Dynarksi (2008) show that much of this trend is explained not by the increases in legal minimum age at school entry that have been implemented in many states, but rather by parental decisions to hold back children who are eligible to start kindergarten. This practice of "red-shirting" is seen more often among groups with higher socioeconomic status, and is especially common for boys. Given that boys are typically thought to mature socially a bit later, their being more likely to be held back is probably not surprising. However, the higher red-shirting rates for more advantaged groups are perhaps more so, given that their children should be the most ready for formal schooling. Anecdotally, parents are concerned that their

\footnotetext{
${ }^{2}$ See http://www.fcps.edu/start/kindergarten.htm for an example of just such a rule.

${ }^{3}$ All of the facts in this paragraph are based on Deming and Dynarski (2008)
} 
child not be the youngest in the cohort, believing that an older child will have a competitive edge. $^{4}$

From the perspective of our paper, it will be interesting to see if physical maturity influences the parental decision of when to start a child in school. ${ }^{5}$ In particular, if children with lower body weight are considered less "ready" for kindergarten and held back, a simple ordinary least squares regression of weight on current grade, controlling for age, will make it appear that school exposure increases weight. To avoid bias from the endogenous choice of school starting age, we will implement what is essentially a regression discontinuity (RD) approach.

Consider the following model:

$$
Y_{i}=f\left(a_{i}, X_{i}, \text { school exposure }_{i}\right) \text {, }
$$

Where $\mathrm{Y}$ is a measure of body weight, and $\mathrm{X}$ is a set of demographics, such as race, gender and parental characteristics. This simple model, when estimated via OLS (and using actual grade as the measure of school exposure) would be expected to be biased by the endogeneity of the school starting decision. This is this version of the model that we start with, in order to investigate the role of parental decision-making. We then move to an $\mathrm{RD}$ specification, using a dummy variable for "making the cutoff" as the measure of school exposure. Throughout, "making the cutoff" implies having a birthday that falls either on or in the six months prior to the school entry cutoff in one's state of residence. Finally, we combine the RD and straightforward regression approaches by measuring school exposure with actual grade, but using the dummy for making the cutoff as an instrument.

\footnotetext{
${ }^{4}$ It is not clear from the literature that there is any lasting advantage to being relatively older, and there remains the possibility that by starting older, the minimum drop-out age will apply at lower grades, resulting in less total education received.

${ }^{5}$ Physical and emotional maturity may be especially correlated for premature births, as the child's developmental age may be better measured by "age since conception" and the physical and developmental effects of prematurity may linger.
} 


\section{Data}

We mainly use data from the Early Childhood Longitudinal Study - Kindergarten Cohort of 1998 (ECLS-K) to investigate the impact of school exposure on children's weight. If the data had been collected on, say, a single birth cohort regardless of the grade attended by the child, it would be relatively straightforward to implement our RD approach. In such a case, for example, we would be able to compare a child born on August 31, 1992 to one born on September 2, 1992. If both children complied with the September 1 school entry-age cutoff rule, and we weighed them both when they were exactly 6 years and 8 months old (approximately May 1, 1999), then the August-born child would be in first grade at the time of measurement and the Septemberborn child would be in kindergarten. Both children have approximately the same age, but the August-born child has (essentially exogenously) one additional year of schooling. We would then attribute any difference in weight between the children to the impact of the additional year of school.

In practice, though, constructing the comparison is more complicated because the data follows only a single grade-based cohort. All of the children in the ECLS-K were in kindergarten in the fall of 1998. The key feature of the data that allows us to construct the RD is that the children are weighed and measured near the end of both kindergarten and first grade. Thus, comparing measurements from younger starters in first grade to those from older starters in kindergarten will successfully compare similar-aged children with different exposure to school. To continue the example described in the paragraph above (and assuming compliance with a September 1 age-entry cutoff), in order to be in the 1998-99 kindergarten cohort a September-born child would be born in 1992, while an August-born child would be born in 1993. When the kindergartners are weighed and measured on May 1, 1999 after nearly 1 year in 
school, the September-born child is approximately 6 years 8 months old, while the child born on August 31 is almost a year younger (almost 5 years 8 months old). When they are weighed in first grade at the end of their second year in school, the September- and August-born children are approximately aged 7 years 8 months, and 6 years 8 months, respectively. Therefore, in order to compare the two children at approximately the same age but (exogenously) different years of school exposure, we would compare the September-born child in measured in kindergarten with the August-born child in measured in first grade, when each is about 6 years 8 months old.

Table 1 lists the age distribution at the point in time that the students are weighed and measured in both kindergarten and first grade. The data are shaded to illustrate how we choose one measurement per child from the spring kindergarten and spring first grade waves of the ECLS-K panel to create our final cross-sectional data set. For simplicity, the table and exposition below use a September 1 cutoff date. In fact, while this is the modal cutoff, there are 14 different cutoff dates employed by the states and we use the cutoff appropriate for each student's state of residence. ${ }^{6}$ In this example, we use the measurement taken when the student's age is between 6 years 3 months and 7 years 2 months. Among entry-age compliers, this amounts to using the kindergarten measurement for those born September - February (the "older starters"), and the first grade measurement for those born March - August (the "younger starters"). Since we measure age relative to the cutoff in days, the September and August students will be only a few days different in age at the time of observation. More generally, we use a 12-month range of age centered on the age at the end of kindergarten of the youngest complier with a state's school entry cutoff.

\footnotetext{
${ }^{6}$ We use the 1998 cutoff dates specified in Datar (2004). Thirty eight percent of the children live in states using a September 1 cutoff and 70 percent are subject to cutoffs in August, September or October.
} 
There are two types of non-compliers in the ECLS-K kindergarten cohort. First are students who would have entered kindergarten in the year prior to the ECLS-K cohort, but delayed entry, so that instead of entering school when they had recently turned five years old, they delayed until they were six. These students were born between March and August of 1992, and, in the case of the September 1 cutoff illustrated in Table 1, range between ages 6 years 9 months and 7 years 2 months when they are measured in kindergarten. For these students, we use the measurement taken in kindergarten. The second type of non-compliance comes from students who miss the cutoff date but nonetheless start school early before they reach age five. In the example, these students were born between September 1993 and February 1994, and when they are measured in first grade are between 6 years and 3 to 8 months old.

Table 2 illustrates how the sample is arranged to provide one observation per child that is measured when the child fits into the desired age range, and is assigned an age relative to the state cutoff for the purposes of implementing the regression discontinuity design. Note that we limit our sample to the two years of birth dates implied by Table $2 .^{7}$ That is, all individuals are born in either the 6 months before/after the current year cutoff (the right side of the top panel/left side of the bottom panel), or the 6 months before/after the previous year cutoff (the right side of the bottom panel/left side of the top panel).

If all children complied with the state laws, we would have a sharp discontinuity, and would simply compare the left-side of the top panel of Table 2 with the right-side. In reality, the presence of non-compliers makes the discontinuity a fuzzy one. First, there are some younger starters (the left-side of the bottom panel) who miss the cutoff, but are nonetheless exposed to an extra year of school. Far more common are the "red-shirts" or older starters (the right-side of the bottom panel) who make the cutoff, but are not exposed to the extra year of school. The actual

\footnotetext{
${ }^{7}$ This uses $97 \%$ of the sample, excluding mainly those who delayed starting school by over a year.
} 
relationship between age (relative to cutoff) and years of school exposure is shown in Figure 1.

The dots on the figure are averages of the dependent variable across 7-day bins. Observations to the right of the cutoff (represented by a vertical line at $\mathrm{x}=0$ ) are predicted to have more school exposure. While the discontinuity is clear, it is not as sharp as it would be in a world with only compliers.

The maintained assumption in an RD approach like this is that there is no other variable that changes discretely at the entry cutoff. In Figure 2, we demonstrate that there is no discontinuity in calendar age measured in days. Our sample selection method has ensured that calendar age increases smoothly with age relative to the school entry cutoff. As a result, the children on either side of the entry cutoff are just days apart in age, but have been exposed to sharply different amounts of school. Adding further credibility to our identification strategy, there are also no sharp differences at the entry age cutoff along any other background characteristic (figures available upon request). ${ }^{8}$

We supplement the ECLS-K results using data from the National Longitudinal Survey of Youth 1979 Mother-Child matched file (NLSY79). The NLSY79 began in 1979 by surveying 12,682 individuals born between 1957 and 1964. Children of the 6,283 female NLSY79 respondents began to be surveyed in 1986 and have been followed up every two years since then. It is these children who form the base of our NLSY79 sample. Note, however, that the sample

\footnotetext{
${ }^{8}$ There is one minor drawback to using the ECLS-K data: we are missing the very small group of students who deviate from the normal patterns. In particular, to obtain a fully representative sample of children born in August, we would want to observe three groups of students: those that start on time, those that start a year late (the "redshirters"), and the extremely small group (1 student in the ECLS-K) that starts a year early even though that would make them extremely young relative to their grade cohort. In the ECLS-K data, these groups are born in August 1993, August 1992, and August 1994, respectively. We cannot include any students born in August 1994 because we do not observe a weight measurement for them during the proper age range (between 6 years 3 months and 7 years 2 months). We have the reverse problem with September-born students. While we observe those who start on time (born 1992) and those who start early (born 1993), we are forced to omit the 6 students who delay school entry an extra year even though they would have been among the oldest students in their cohort if they complied with the entry cutoff (born 1991). To the extent these missing cases are inherently heavier/lighter than average, a small bias towards OLS will result.
} 
children are not representative of all children in the United States. In particular, given the maternal sample, there is an over-representation of children born to young mothers. We therefore limit our sample to children with mothers who were between the ages of 19 and 40 at the time of their birth. The NLSY79 also has some problems with data accuracy. In particular, we exclude observations with recorded BMI outside the range of measured BMI values in the National Health and Nutrition Examination Survey (NHANES) for the corresponding age group. ${ }^{9}$ We then use two subsamples to supplement the ECLS-K results. First, we use only children who were age 5 or 6 in the fall of the survey year, to mimic the ECLS-K cohort sample. Second, we expand the sample to all pre-adolescent children age 5 to 10 .

While the NLSY79 samples do not have the drawback of being a grade-cohort sample like the ECLS-K, they have their own drawbacks. First, the ratio of individuals reported to be in a grade higher than predicted (based on their birth date and the school starting date for their state) relative to those in a grade lower than predicted is higher than one would expect given redshirting patterns. Second, the sample is relatively small, limiting statistical power, especially in the RD approach. Thus, our main use of the NLSY79 data is to compare the point estimates to those from the ECLS-K.

\section{Results}

\section{A. Main ECLS-K Models}

Table 3 presents the main results of our analysis, based on the ECLS-K sample. ${ }^{10}$ Recall that the basic model took the form:

$$
Y_{i}=f\left(a_{i g}, X_{i}, \text { school exposure }\right) \text {. }
$$

\footnotetext{
${ }^{9}$ For the mothers, this implies dropping observations outside the range of 15 to 66 and for the children, outside the range of 11 to 40 .

${ }^{10}$ Appendix Table 1 provides summary statistics.
} 
In each of the models in this table, the function of age $e_{i}$ that we use is a cubic of age in days (relative to the starting cutoff) that is estimated separately before and after the cutoff. In all but column (1), $\mathrm{X}_{\mathrm{i}}$ includes dummies for race, gender, mother's education and state. Only state dummies are included in column (1). The measures of school exposure $\mathrm{i}_{\mathrm{i}}$ and of $\mathrm{Y}_{\mathrm{i}}$ used vary by column and panel and are indicated in the table and described in more detail below. All models use standard errors that are robust to heteroskedasticity and within-school correlation in the error terms. ${ }^{11}$

The top panel presents the simple OLS estimate of the model using actual school exposure. Since in this sample individuals are either in kindergarten or in first grade (i.e., have 1 or 2 years of school), this exposure variable is simply a dummy variable for being observed in first grade. Columns (1) and (2) estimate the relationship to $\ln (\mathrm{BMI})$. Controlling for additional demographics makes very little difference, and in both cases, greater school exposure is positively, and statistically significantly, correlated with body weight. The same is true in columns (3) and (4), where the probability of being obese and overweight, respectively are significantly higher with more school exposure. In column (5), the relationship with the probability of being underweight is negative, but not significant at conventional levels.

As noted above, though, to the extent that parental decisions to comply with the starting date cutoff are influenced by factors correlated with body weight, then these OLS estimates will be seriously biased. Thus, the most appropriate interpretation of this top panel is not that school exposure causes children to gain weight. Rather, it appears that the determination of school "readiness" that parents make either includes body weight explicitly, or includes things that are highly correlated with it, since the younger starters are significantly heavier than the older starters when observed at the same age.

\footnotetext{
${ }^{11}$ Clustering standard errors on centered age (in days) yields similar inferences.
} 
The second panel substitutes predicted school exposure for actual school exposure, meaning we use a dummy variable for being predicted to be in first grade ("making the cutoff" in the ECLS-K), given the child's birth date relative to the school entry cutoff date. Thus, this panel implements the regression discontinuity approach. The effect of removing the endogeneity of the school starting decision is clear: school exposure is now negatively related to $\ln (\mathrm{BMI})$, as shown in columns (1) and (2). However, the estimated effect is not statistically significant. Appendix Figure 1 illustrates this result, plotting weekly means of $\ln (\mathrm{BMI})$ (as in Figure 1) as well as predicted fits from the RD specification. While the impact on the probability of being overweight also becomes negative, the estimated effect on the probability of being obese remains positive, albeit smaller than in the first panel, and not statistically significant. Interestingly, the negative effect in column (4) comes closer to being significant than any of the other columns, but the p-value is still just 0.156 . Appendix Figure 2 illustrates this model. Finally, as was the case with the OLS model in the top panel, there is no discernible effect of school exposure on the probability of being underweight, although in this RD model the point estimate is very close to zero and the p-value is very high.

While these RD models are a straightforward approach to using the variation in school exposure stemming from school starting dates, they can also be thought of simply as the reduced form to an instrumental variables approach, which is carried out in the bottom two panels. Using whether a child is predicted to be in first grade (based on age and school cutoff date) as an instrument for actually being in first grade results in a very strong first stage. As was clear in Figure 1, however, the presence of noncompliers means the prediction is not perfect, giving us a coefficient of 0.64 instead of the 1.0 that would be obtained with perfect compliance. The IV estimates in the bottom panel are consistent with the reduced form estimates in the second panel, 
but have essentially just been scaled up to reflect the fuzziness of the discontinuity. ${ }^{12}$ While we are unable to reject that the estimated effects are equal to zero, in all cases except for columns (3) and (5), we can reject that the IV estimates are the same as the OLS estimates. For example, in column (2) the IV point estimate suggests that an additional year of school reduces BMI by 1.6 percent, and this effect is significantly different from the OLS point estimate that suggests that an additional year of school increases BMI by 1.6 percent. Given the pattern of OLS versus IV estimates, it is clear that there is a positive bias in the OLS estimates. It does appear that parents are taking into consideration some factor(s) correlated with body weight when deciding whether to comply with school starting date cutoffs. The IV estimates suggest that increased school exposure is not likely to (on net) increase body weight. There is also not statistically strong evidence that it decreases body weight.

\section{B. Alternate ECLS-K Models and Subgroup Analyses}

Table 4 repeats the same exercise as in Table 3, but with a set of alternate outcomes. The purpose here is two-fold. First, as a falsification exercise, we look at two physical outcomes that should not be affected by an additional year of school exposure. Column (1) looks at ln(height), while column (2) looks at $\ln$ (birthweight). ${ }^{13}$ The positive and significant coefficients in these columns in the first panel are just further evidence that the OLS models are biased due to parents basing school starting decisions on unobservable characteristics of the child that are correlated with physical attributes. ${ }^{14}$ By focusing on the school starting date cutoffs, though, the spurious significantly positive effect is removed. For height, the RD and IV point estimates are

\footnotetext{
12 Thus, looking at column (4), for example, $-0.0441 / 0.638 \approx-0.0692$.

${ }^{13}$ Technically, school exposure could affect height if education increases nutritional quality sufficiently, but this is unlikely to be the case in the United States when comparing kindergarteners to first graders.

${ }^{14}$ Obviously, parents may actually be making decisions based on height (e.g. not wanting the child to be the smallest in class) or on birthweight (e.g. basing decisions for premature children based on age since conception). The key is that the results in this panel cannot represent causal estimates, and the same is true of Table 3.
} 
essentially zero, while for birth weight the positive estimate is cut almost to a third of the OLS coefficient, and is not statistically significantly different from zero.

Column (3) documents that the RD and IV approaches used here find strong impacts of school exposure on student test scores, as the literature suggests. Column (3) is the score on a math test, standardized across both grades. The expectation is that when standardizing across grades, having more school exposure is helpful, since a child with two years of school has presumably learned more than one with just a single year of school. Comparing the top panel with the bottom, we first again see the positive bias in the OLS estimates. Since parents are more likely to hold back a child that is less prepared academically, and vice versa, school exposure will appear to have a more positive impact on academic outcomes. While the IV estimates are less positive, they are very precisely estimated and significantly different from both zero and the OLS estimates. ${ }^{15}$ Thus, we see that children are learning something in school - an extra year of schooling increases performance on the standardized test by just over three-quarters of a standard deviation.

At this point, it appears that there is no deleterious effect of school exposure on children's weight outcomes. If anything, the point estimates imply a small, but insignificant, reduction in BMI and the probability of being overweight. If being in school is better for weight outcomes, what are the potential mechanisms? One clear possibility is that being in school reduces opportunities for eating outside of prescribed times. As shown in Anderson, Butcher and Schanzenbach (2011), cutting the equivalent of one Oreo cookie per school day (about 300 calories per week) out of a child's diet over the course of a school year can reduce BMI by over 2 percent. Thus, a reduction in snacking upon going to school can reduce body weight. At the

\footnotetext{
${ }^{15}$ Appendix Figure 3 graphs the results of the reduced form model from column (3), making clear how much more precise the estimates are for this outcome compared to the body weight results from the previous table.
} 
same time, much of the school day is spent sitting still and a reduction in activity can increase body weight. However, most children are not continuously active when out of school, and school does (usually) provide recess and physical education. For some children, providing such an opportunity for physical activity may actually increase their daily exercise.

Recall, however, that some studies have shown deleterious effects of certain school environments. In the case of exposure to junk food in schools, this exposure is relatively low in kindergarten and first grade, with the largest exposure coming in high school. The positive effect on obesity found in Anderson and Butcher (2006), for example, was based on a sample of adolescents. For the comparison in this paper, between being exposed to just kindergarten versus first grade, exposure to junk food in school is unlikely to play a major role. However, exposure to school lunch is likely to be more important. As shown in Schanzenbach (2009), eating the school lunch, even at young ages, results in a higher probability of overweight. With this effect in mind, we repeat the models of Table 3, estimated separately for those who report eating the school lunch and those who report not eating it. Tables $5 \mathrm{a}$ and $5 \mathrm{~b}$ present these results.

The basic patterns seen in both tables are similar to those from Table 3 , in that positive OLS point estimates generally reverse to negative IV point estimates. However, these point estimates are much more negative for the sample in Table $5 \mathrm{~b}$ of those not eating school lunches. In fact, the effect on the probability of overweight is marginally significant, with a p-value of 0.07. ${ }^{16}$ It is important to remember that eating or not eating school lunch is not exogenous. Poorer children qualifying for free or reduced-price lunch are more likely to eat school lunch, for example. This likely difference in socioeconomic status may be the driving force behind the difference in the first stages across Tables $5 \mathrm{a}$ and $5 \mathrm{~b}$. While in both cases the first stage is very strong, the point estimate is much larger in Table 5a, implying that there are fewer non-compliers

\footnotetext{
${ }^{16}$ The results from the reduced form model are shown in Appendix Figure 4.
} 
in that sample. Recall the earlier discussion of red-shirting being mainly a higher socioeconomic phenomenon, which is consistent with these results.

We next investigate whether the finding that school exposure may be healthful provided one does not eat lunch is not just a reflection of differences across the socioeconomic class of school-lunch-eaters and non-school-lunch-eaters. Thus, we also split the sample by whether the child's family had ever participated in a broader set of poverty-alleviation programs. In addition to ever getting free or reduced-price lunch, we included anyone who reported being food insecure, or participating in Food Stamps, Head Start, or WIC. Appendix Tables 2a and 2b present the results of this exercise. Whereas like Tables $5 \mathrm{a}$ and $5 \mathrm{~b}$, the first stage estimate is much higher in Appendix Table 2a than 2b, the differences in results are less noticeable and are generally in line with the overall sample results in Table 3. That said, the point estimates are slightly more negative for the group of poverty program non-participants, but unlike those not eating school lunch, the results never come close to being statistically significantly different from zero.

\section{NLSY79 Models}

Based on the estimates from the ECLS-K data using variation in school exposure due to state school starting-age cutoff dates, there is no evidence that being in school, per se, contributes to children's weight gain. If anything, it appears possible that school is helpful, with the possible exception of those eating the school lunch. To assess the robustness of these findings across a wider age range, in this section we investigate similar models estimated with the children of the 
NLSY. Appendix Tables 3 and 4 present results similar to those in Table 3 for two different samples of NLSY children. ${ }^{17}$

Appendix Table 3 limits the sample to children who were five or six in the fall of the survey year, and thus, should most closely parallel the ECLS-K sample. Unfortunately, the small samples result in estimates even less precise than those from the ECLS-K. In fact, it is not even possible to reject the null hypothesis that the OLS and IV models are the same. That said, there is no evidence from these NLSY results that our previous conclusions are seriously misguided. Even when we expand the NLSY sample to all pre-adolescent children aged five to ten, in Appendix Table 4, the imprecision remains. ${ }^{18}$

Ultimately, what we take from these estimates is confirmation of our ECLS-K findings. The fact that we do not find deleterious effects of school exposure is reasonable evidence that those effects are unlikely to exist. At the same time, being in school may be better for children than we are able to estimate, but it seems safe to conclude that one's best bet for reaping the weight benefits from school exposure will come for those not participating in the school lunch program.

\section{Conclusions}

Public health policymakers have tended to focus on schools as an important battleground in the fight against childhood obesity, feeling that the current school environment may be a contributing factor to the increase in childhood obesity (e.g. Haskins et al. 2006). While studies have found that eating school lunches and being exposed to junk food in schools may result in

\footnotetext{
${ }^{17}$ In both tables, standard errors are robust to heteroskedasticity and within-family correlation in the error terms. School entry cutoff dates by state and year were collected by the authors from state session laws and assigned to individuals based on birthdate and state of residence at age five.

${ }^{18}$ Results for alternative outcomes are available on request. Even using standardized math scores as in column (3) of Table 4 does not result in statistically significant results for 5-6 year-olds, although 10 percent significance is obtained with the expanded age group.
} 
weight gain (Schanzenbach 2009, Anderson and Butcher 2006), these studies only show that some school environments are worse than others. They do not necessarily imply that the school environment in general is worse than the non-school environment. In fact, other studies indicate that summer is worse than the school year for weight gain (von Hippel et al. 2007) and that teen girls with more education are less likely to be overweight (Zhang 2007).

In this paper, we use school starting age cutoff dates to compare weight outcomes for similar age children with one versus two years of school exposure. As is the case with academic outcomes, school exposure is related to unobserved determinants of weight outcomes. If one does not account for this endogeneity, it appears that an additional year of school exposure results in a greater BMI and a higher probability of being overweight or obese. When actual exposure is instrumented with predicted school exposure in a regression discontinuity framework, the significant positive effects disappear. However, while the point estimates generally become negative and are significantly different from the OLS results, they are not statistically significantly different from zero. One exception is the effect of school exposure on the probability of being overweight for children who do not participate in the school lunch program. However, we are cautious in interpreting this result as entirely causal, since the sample is based on the endogenous decision whether to participate in the school lunch program.

The fact that the OLS and IV results are statistically significantly different is somewhat interesting in its own right. Researchers have long recognized that endogeneity of the schoolstarting decision biases estimates of the effect of schooling on academic outcomes, as parents will take into account a child's academic readiness (unobserved to the researcher) in making that decision. Our results make clear that either these unobserved traits are highly correlated with physical attributes like BMI and overweight, or these physical traits are directly taken into 
account. Our findings lead us to conclude that school exposure, per se, seems unlikely to cause weight gain, and may even be beneficial. 


\section{References}

Anderson, Patricia M. and Kristin F. Butcher. 2006. "Reading, Writing and Refreshments: Do School Finances Contribute to Childhood Obesity?" Journal of Human Resources 41(3): 467-494.

Anderson, Patricia M., Kristin F. Butcher and Diane Whitmore Schanzenbach. 2011. "School Policies and Children's Obesity." Current Issues in Health Economics. Dan Slotje and Rusty Tchernis, eds.

Cascio, Elizabeth U. and Ethan G. Lewis. 2006. "Schooling and the Armed Forces Qualifying Test: Evidence from School-Entry Laws.” Journal of Human Resources 41(2): 294-318.

Cutler, David M. and Adriana Lleras-Muney. 2010. "Understanding Differences in Health Behaviors by Education.” Journal of Health Economics 29(1): 1-28.

Datar, Ashlesha. 2004. "Does Delaying Kindergarten Entrance Give Children a Head Start?" Economics of Education Review 25: 43-62.

Deming, David and Susan Dynarski. 2008. “The Lengthening of Childhood.” Journal of Economic Perspectives 22(3): $71-92$.

Dobkin, Carlos and Fernando Ferreira. 2010. "Do School Entry Laws Affect Educational Attainment and Labor Market Outcomes?” Economics of Education Review 29(1): 40-54.

Gormley, William T. and Ted Gayer. 2005. "Promoting School Readiness in Oklahoma: An Evaluation of Tulsa's Pre-K Program.” Journal of Human Resources 40(3): 533-558.

Haskins, Ron, Christina Paxson and Elisabeth Donahue. 2006. "Policy Brief: Fighting Obesity in the Public Schools." The Future of Children.

McCrary, Justin and Heather Royer. Forthcoming. "The Effect of Female Education on Fertility and Infant Health: Evidence from School Entry Laws Using Exact Date of Birth." American Economic Review.

Schanzenbach, Diane Whitmore. 2009. "Do School Lunches Contribute to Childhood Obesity?" Journal of Human Resources 44(3): 684 - 709.

Taras, Howard and William Potts-Datema. 2005. "Obesity and Student Performance at School." The Journal of School Health 75(8): 291-295.

Von Hippel, Paul T. and Brian Powell, Douglas B. Downey and Nicholas J. Rowland. 2007. "The Effect of School on Overweight in Childhood: Gain in Body Mass Index During the School Year and During Summer Vacation." American Journal of Public Health 97 (4): 696-702. 
Zhang, Ning. 2007. "Does Early School Entry Prevent Youth Obesity?" Available at SSRN: http://ssrn.com/abstract=992235 
Figure 1: The Regression Discontinuity in Actual Grade (ECLS-K)

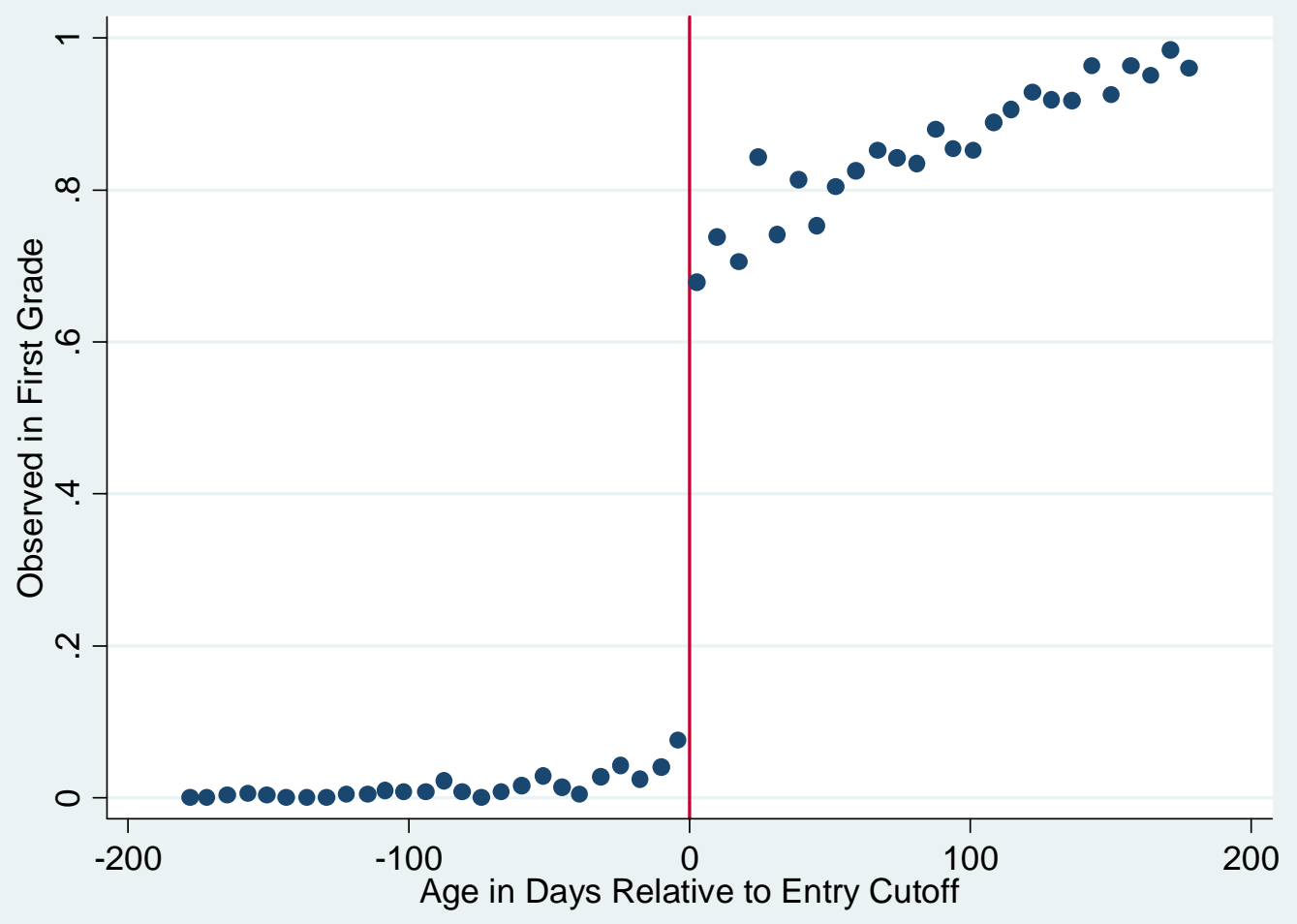

Figure 2: Actual Age is Smooth through the Discontinuity in Grade (ECLS-K)

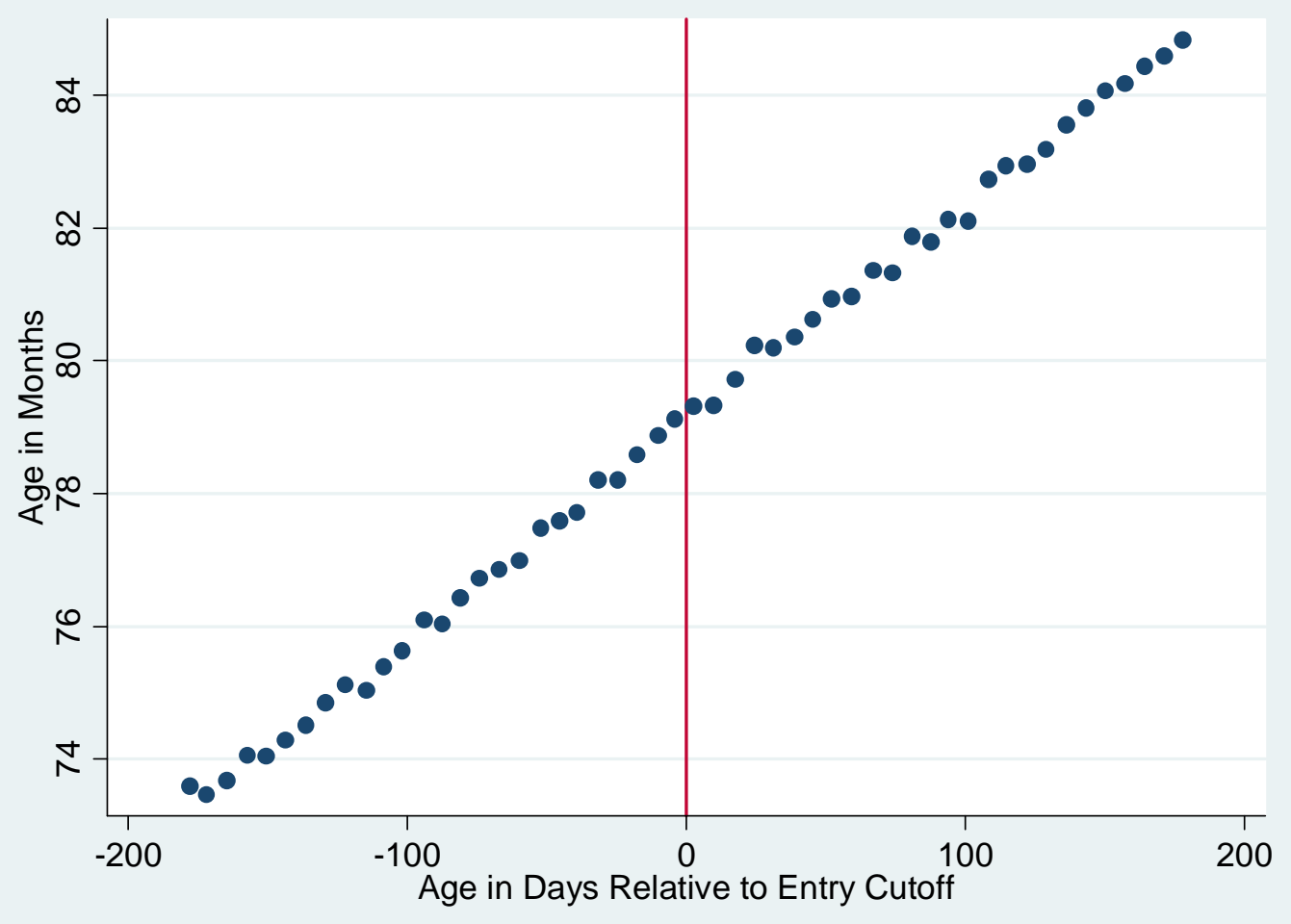


Table 1

Illustrating the Creation of the Analysis Sample for ECLS-K, Assuming a September 1 School Start Cutoff

\begin{tabular}{|c|c|c|c|}
\hline Birthdate & Age on May 1 (K) & Age on May 1 (1 $\mathbf{1}^{\text {st }}$ & \\
\hline March 92 & 7 years 2 months & 8 years 2 months & \\
\hline April 92 & 7 years 1 months & 8 years 1 months & \\
\hline May 92 & 7 years 0 months & 8 years 0 months & \\
\hline June 92 & 6 years 11 months & 7 years 11 months & \\
\hline July 92 & 6 years 10 months & 7 years 10 months & \\
\hline August 92 & 6 years 9 months & 7 years 9 months & \\
\hline September 92 & 6 years 8 months & 7 years 8 months & Compare to Aug 93 \\
\hline October 92 & 6 years 7 months & 7 years 7 months & \\
\hline November 92 & 6 years 6 months & 7 years 6 months & \\
\hline December 92 & 6 years 5 months & 7 years 5 months & \\
\hline January 93 & 6 years 4 months & 7 years 4 months & \\
\hline February 93 & 6 years 3 months & 7 years 3 months & \\
\hline March 93 & 6 years 2 months & 7 years 2 months & \\
\hline April 93 & 6 years 1 months & 7 years 1 months & \\
\hline May 93 & 6 years 0 months & 7 years 0 months & \\
\hline June 93 & 5 years 11 months & 6 years 11 months & \\
\hline July 93 & 5 years 10 months & 6 years 10 months & \\
\hline August 93 & 5 years 9 months & 6 years 9 months & Compare to Sep 92 \\
\hline September 93 & 5 years 8 months & 6 years 8 months & \\
\hline October 93 & 5 years 7 months & 6 years 7 months & \\
\hline November 93 & 5 years 6 months & 6 years 6 months & \\
\hline December 93 & 5 years 5 months & 6 years 5 months & \\
\hline January 94 & 5 years 4 months & 6 years 4 months & \\
\hline February 94 & 5 years 3 months & 6 years 3 months & \\
\hline
\end{tabular}

Notes: Complier birthdates are shaded in green. Those compliers reaching age 5 in the six months before the cutoff are considered to be younger starters, and we look at their assessment in first grade. For the even younger non-compliers, we also use first grade. All of these younger starters are shaded in yellow. Those compliers reaching age 5 in the six months after the previous-year cutoff are considered to be older starters, and we look at their assessment in kindergarten. For the even older non-compliers, we also use kindergarten. All of these older starters are shaded in blue. 
Table 2

Arrangement of Data for the Regression Discontinuity Approach (ECLS-K), Assuming a September 1 School Start Cutoff

\begin{tabular}{|c|c|c|c|c|c|c|c|c|c|c|c|c|}
\hline $\begin{array}{c}\text { Centered } \\
\text { Age }\end{array}$ & -6 & -5 & -4 & -3 & -2 & -1 & 0 & 1 & 2 & 3 & 4 & 5 \\
\hline $\begin{array}{c}\text { Birthdate } \\
\text { (compliers) }\end{array}$ & $\begin{array}{c}\text { Feb } \\
93\end{array}$ & $\begin{array}{l}\text { Jan } \\
93\end{array}$ & $\begin{array}{c}\text { Dec } \\
92\end{array}$ & $\begin{array}{l}\text { Nov } \\
92\end{array}$ & $\begin{array}{l}\text { Oct } \\
92\end{array}$ & $\begin{array}{l}\text { Sep } \\
92\end{array}$ & $\begin{array}{l}\text { Aug } \\
93\end{array}$ & $\begin{array}{l}\text { Jul } \\
93\end{array}$ & $\begin{array}{c}\text { Jun } \\
93\end{array}$ & $\begin{array}{l}\text { May } \\
93\end{array}$ & $\begin{array}{c}\text { Apr } \\
93\end{array}$ & $\begin{array}{c}\text { Mar } \\
93\end{array}$ \\
\hline $\begin{array}{c}\text { Age on } \\
\text { May } 1\end{array}$ & $6-3$ & $6-4$ & $6-5$ & $6-6$ & $6-7$ & $6-8$ & 6-9 & $\begin{array}{l}6- \\
10\end{array}$ & $\begin{array}{l}6- \\
11\end{array}$ & $7-0$ & $7-1$ & $7-2$ \\
\hline $\begin{array}{l}\text { Grade in } \\
\text { which } \\
\text { observed }\end{array}$ & $\mathrm{k}$ & $\mathrm{k}$ & $\mathrm{k}$ & $\mathrm{k}$ & $\mathrm{k}$ & $\mathrm{k}$ & 1 & 1 & 1 & 1 & 1 & 1 \\
\hline $\begin{array}{c}\text { Birthdate } \\
\text { (non- } \\
\text { compliers) }\end{array}$ & $\begin{array}{c}\text { Feb } \\
94\end{array}$ & $\begin{array}{c}\text { Jan } \\
94\end{array}$ & $\begin{array}{c}\text { Dec } \\
93\end{array}$ & $\begin{array}{c}\text { Nov } \\
93\end{array}$ & $\begin{array}{l}\text { Oct } \\
93\end{array}$ & $\begin{array}{c}\text { Sep } \\
93\end{array}$ & $\begin{array}{l}\text { Aug } \\
92\end{array}$ & $\begin{array}{l}\text { Jul } \\
92\end{array}$ & $\begin{array}{c}\text { Jun } \\
92\end{array}$ & $\begin{array}{l}\text { May } \\
92\end{array}$ & $\begin{array}{c}\text { Apr } \\
92\end{array}$ & $\begin{array}{c}\text { Mar } \\
92\end{array}$ \\
\hline $\begin{array}{l}\text { Age on } \\
\text { May } 1 \\
\end{array}$ & $6-3$ & $6-4$ & $6-5$ & $6-6$ & $6-7$ & $6-8$ & $6-9$ & $\begin{array}{l}6- \\
10 \\
\end{array}$ & $\begin{array}{l}6- \\
11\end{array}$ & $7-0$ & $7-1$ & $7-2$ \\
\hline $\begin{array}{c}\text { Grade in } \\
\text { which } \\
\text { observed }\end{array}$ & 1 & 1 & 1 & 1 & 1 & 1 & $\mathrm{k}$ & $\mathrm{k}$ & $\mathrm{k}$ & $\mathrm{k}$ & $\mathrm{k}$ & $\mathrm{k}$ \\
\hline
\end{tabular}

Notes: This table is meant to be illustrative of the regression discontinuity at 0 , where children on either side of the discontinuity are approximately the same age, but are a year apart in school. Centered age is actually measured in days, not months, see text for details. Complier birthdates are shaded in green. Those compliers reaching age 5 in the six months before the cutoff are considered to be younger starters, and we look at their assessment in first grade. For the even younger non-compliers, we also use first grade. All of these younger starters are shaded in yellow. Those compliers reaching age 5 in the six months after the previous-year cutoff are considered to be older starters, and we look at their assessment in kindergarten. For the even older non-compliers, we also use kindergarten. All of these older starters are shaded in blue. 
Table 3

Estimated Effects of School Exposure on Body Weight

(Clustered Standard Errors in Parentheses)

\begin{tabular}{lccccc}
\hline \hline OLS Regression & $(1)$ & $(2)$ & $(3)$ & $(4)$ & $(5)$ \\
\hline & $\ln (\mathrm{BMI})$ & $\ln (\mathrm{BMI})$ & Obese & Overwt. & Underwt. \\
In $1^{\text {st }}$ Grade & 0.018 & 0.016 & 0.035 & 0.045 & -0.007 \\
& $(0.004)$ & $(0.004)$ & $(0.010)$ & $(0.014)$ & $(0.006)$ \\
p-value & 0.000 & 0.000 & 0.000 & 0.002 & 0.191 \\
Observations & 12,754 & 12,754 & 12,754 & 12,754 & 12,754 \\
R-squared & 0.014 & 0.026 & 0.014 & 0.017 & 0.013 \\
\hline Reduced Form Regression & $(1)$ & $(2)$ & $(3)$ & $(4)$ & $(5)$ \\
\hline & $\ln (\mathrm{BMI})$ & $\ln (\mathrm{BMI})$ & Obese & Overwt. & Underwt. \\
\hline Predicted to be in $1^{\text {st }}$ Grade & -0.010 & -0.011 & 0.011 & -0.044 & -0.002 \\
& $(0.009)$ & $(0.009)$ & $(0.023)$ & $(0.031)$ & $(0.012)$ \\
p-value & 0.281 & 0.246 & 0.652 & 0.156 & 0.893 \\
Observations & 12,754 & 12,754 & 12,754 & 12,754 & 12,754 \\
R-squared & 0.013 & 0.025 & 0.014 & 0.016 & 0.013 \\
\hline First Stage Regression & $(1)$ & $(2)$ & $(3)$ & $(4)$ & $(5)$ \\
\hline & $\mathrm{In} 1^{\text {st }} \mathrm{Gr}$. & $\mathrm{In} 1^{\text {st }} \mathrm{Gr}$. & $\mathrm{In} 1^{\text {st }} \mathrm{Gr}$. & In $1^{\text {st }} \mathrm{Gr}$. & In $1^{\text {st }} \mathrm{Gr}$. \\
\hline Predicted to be in $1^{\text {st }}$ Grade & 0.635 & 0.638 & 0.638 & 0.638 & 0.638 \\
& $(0.025)$ & $(0.025)$ & $(0.025)$ & $(0.025)$ & $(0.025)$ \\
p-value & 0.000 & 0.000 & 0.000 & 0.000 & 0.000 \\
Observations & 12,754 & 12,754 & 12,754 & 12,754 & 12,754 \\
R-squared & 0.739 & 0.743 & 0.743 & 0.743 & 0.743 \\
\hline Instrumental Variables & $(1)$ & $(2)$ & $(3)$ & $(4)$ & $(5)$ \\
\hline & $\ln (\mathrm{BMI})$ & $\ln (\mathrm{BMI})$ & Obese & Overwt. & Underwt. \\
In 1 ${ }^{\text {st }}$ Grade & -0.016 & -0.016 & 0.016 & -0.069 & -0.002 \\
& $(0.014)$ & $(0.014)$ & $(0.036)$ & $(0.049)$ & $(0.018)$ \\
p-value & 0.282 & 0.247 & 0.652 & 0.158 & 0.893 \\
Observations & 12,754 & 12,754 & 12,754 & 12,754 & 12,754 \\
R-squared & 0.010 & 0.021 & 0.014 & 0.012 & 0.013 \\
\hline \hline
\end{tabular}

Notes: Standard Errors are adjusted for heterogeneity and within school correlation. Column 1 controls for a cubic in age in days relative to the state specific school starting age cutoff, and an interaction of the age variables with a dummy for whether the individual "made" the cutoff, and state fixed effects. Column (2) adds dummy variables for race/ethnicity, sex, and maternal education: African American, Hispanic, and other race, female, mother dropped out of high school, mother completed high school, mother's education missing. Mother's education above high school (and not missing) is the omitted group. "In $1^{\text {st }}$ Grade" is a dummy variable equal to 1 if we use the individual's observation from the first grade interview and zero otherwise. "Predicted to be in $1^{\text {st }}$ Grade" is a dummy variable equal to 1 if the child was born on or before the birthday cutoff for beginning kindergarten in his/her state in 1998. The right hand side variables are the same in Columns (2)-(5). 
Table 4

Estimated Effects of School Exposure on Alternative Outcomes (Clustered Standard Errors in Parentheses)

\begin{tabular}{|c|c|c|c|}
\hline OLS Regression & (1) & (2) & (3) \\
\hline & \multirow{3}{*}{$\ln$ (height) } & \multirow{3}{*}{$\ln$ (birthweight) } & Math Score: \\
\hline \multirow{4}{*}{ In $1^{\text {st }}$ Grade } & & & Standardized \\
\hline & & & Across Grades \\
\hline & 0.009 & 0.031 & 1.006 \\
\hline & $(0.002)$ & $(0.008)$ & $(0.030)$ \\
\hline p-value & 0.000 & 0.000 & 0.000 \\
\hline Observations & 12,754 & 11,914 & 12,754 \\
\hline R-squared & 0.141 & 0.035 & 0.408 \\
\hline Reduced Form Regression & (1) & (2) & (3) \\
\hline \multirow{3}{*}{ Predicted to be in $1^{\text {st }}$ Grade } & $\ln ($ height $)$ & $\ln$ (birthweight) & Math: Across \\
\hline & 0.000 & 0.011 & 0.501 \\
\hline & $(0.003)$ & $(0.015)$ & $(0.059)$ \\
\hline $\mathrm{p}$-value & 0.911 & 0.453 & 0.000 \\
\hline Observations & 12,754 & 11,914 & 12,754 \\
\hline R-squared & 0.138 & 0.034 & 0.340 \\
\hline First Stage Regression & (1) & (2) & (3) \\
\hline \multirow{3}{*}{ Predicted to be in $1^{\text {st }}$ Grade } & In $1^{\text {st }}$ Grade & In $1^{\text {st }}$ Grade & In $1^{\text {st }}$ Grade \\
\hline & 0.638 & 0.631 & 0.638 \\
\hline & $(0.025)$ & $(0.026)$ & $(0.025)$ \\
\hline p-value & 0.000 & 0.000 & 0.000 \\
\hline Observations & 12,754 & 11,914 & 12,754 \\
\hline R-squared & 0.743 & 0.743 & 0.743 \\
\hline Instrumental Variables & (1) & (2) & (3) \\
\hline \multirow{3}{*}{ In $1^{\text {st }}$ Grade } & $\ln ($ height $)$ & $\ln$ (birthweight) & Math: Across \\
\hline & 0.001 & 0.017 & 0.786 \\
\hline & $(0.005)$ & $(0.023)$ & $(0.086)$ \\
\hline $\mathrm{p}$-value & 0.911 & 0.452 & 0.000 \\
\hline Observations & 12,754 & 11,914 & 12,754 \\
\hline R-squared & 0.139 & 0.035 & 0.404 \\
\hline
\end{tabular}

Notes: See notes to Table 3 for what control variables are included in each column. Standard Errors are adjusted for heterogeneity and within school correlation. Height is measured in inches. Birthweight is measured in ounces. Math scores are standardized with a of mean zero and a standard deviation of one. Math scores in Column (3) are standardized across grades (being in a higher grade is positively related to scores), and Math scores in column 4 are standardized within grade (being younger for a given grade is negatively related to scores). 
Table 5a

Estimated Effects of School Exposure on Body Weight -School Lunch Program Participants (Clustered Standard Errors in Parentheses)

\begin{tabular}{lccccc}
\hline \hline OLS Regression & $(1)$ & $(2)$ & $(3)$ & $(4)$ & $(5)$ \\
\hline & $\ln (\mathrm{BMI})$ & $\ln (\mathrm{BMI})$ & Obese & Overwt. & Underwt. \\
In $1^{\text {st }}$ Grade & 0.015 & 0.014 & 0.029 & 0.045 & -0.005 \\
& $(0.006)$ & $(0.006)$ & $(0.014)$ & $(0.019)$ & $(0.008)$ \\
p-value & 0.011 & 0.012 & 0.031 & 0.019 & 0.550 \\
Observations & 7,894 & 7,894 & 7,894 & 7,894 & 7,894 \\
R-squared & 0.017 & 0.026 & 0.016 & 0.018 & 0.017 \\
\hline Reduced Form Regression & $(1)$ & $(2)$ & $(3)$ & $(4)$ & $(5)$ \\
\hline & $\ln (\mathrm{BMI})$ & $\ln (\mathrm{BMI})$ & Obese & Overwt. & Underwt. \\
Predicted to be in $1^{\text {st }}$ Grade & -0.007 & -0.007 & 0.004 & -0.021 & -0.007 \\
& $(0.012)$ & $(0.012)$ & $(0.030)$ & $(0.042)$ & $(0.015)$ \\
p-value & 0.554 & 0.583 & 0.886 & 0.625 & 0.634 \\
Observations & 7,894 & 7,894 & 7,894 & 7,894 & 7,894 \\
R-squared & 0.017 & 0.026 & 0.015 & 0.018 & 0.017 \\
\hline First Stage Regression & $(1)$ & $(2)$ & $(3)$ & $(4)$ & $(5)$ \\
\hline & In 1 & In $1^{\text {st }}$ & In $1^{\text {st }}$ & In 1 & In $1^{\text {st }}$ \\
& Grade & Grade & Grade & Grade & Grade \\
Predicted to be in $1^{\text {st }}$ Grade & 0.707 & 0.711 & 0.711 & 0.711 & 0.711 \\
& $(0.029)$ & $(0.029)$ & $(0.029)$ & $(0.029)$ & $(0.029)$ \\
p-value & 0.000 & 0.000 & 0.000 & 0.000 & 0.000 \\
Observations & 7,894 & 7,894 & 7,894 & 7,894 & 7,894 \\
R-squared & 0.786 & 0.788 & 0.788 & 0.788 & 0.788 \\
\hline Instrumental Variables & $(1)$ & $(2)$ & $(3)$ & $(4)$ & $(5)$ \\
\hline & $\ln (\mathrm{BMI})$ & $\ln (\mathrm{BMI})$ & Obese & Overwt. & Underwt. \\
In 1 ${ }^{\text {st }}$ Grade & -0.010 & -0.009 & 0.006 & -0.029 & -0.010 \\
p-value & $(0.017)$ & $(0.017)$ & $(0.042)$ & $(0.059)$ & $(0.022)$ \\
Observations & 0.554 & 0.583 & 0.886 & 0.626 & 0.634 \\
R-squared & 7,894 & 7,894 & 7,894 & 7,894 & 7,894 \\
\hline \hline & 0.015 & 0.024 & 0.015 & 0.017 & 0.017 \\
\hline
\end{tabular}

Notes: See notes to Table 3 for what control variables are included in each column. Standard Errors are adjusted for heterogeneity and within school correlation. The sample used for the estimates in this table is for those reporting that they receive a complete school lunch. 
Table $5 b$

Estimated Effects of School Exposure on Body Weight - School Lunch Non-Participants (Clustered Standard Errors in Parentheses)

\begin{tabular}{|c|c|c|c|c|c|}
\hline OLS Regression & (1) & $(2)$ & (3) & (4) & $(5)$ \\
\hline \multirow{3}{*}{ In $1^{\text {st }}$ Grade } & $\ln (\mathrm{BMI})$ & $\ln (\mathrm{BMI})$ & Obese & Overwt. & Underwt. \\
\hline & 0.014 & 0.012 & 0.041 & 0.033 & -0.009 \\
\hline & $(0.006)$ & $(0.006)$ & $(0.015)$ & $(0.022)$ & $(0.008)$ \\
\hline p-value & 0.020 & 0.040 & 0.004 & 0.127 & 0.263 \\
\hline Observations & 4,860 & 4,860 & 4,860 & 4,860 & 4,860 \\
\hline R-squared & 0.020 & 0.033 & 0.025 & 0.024 & 0.017 \\
\hline \multirow[t]{2}{*}{$\begin{array}{l}\text { Reduced Form } \\
\text { Regression }\end{array}$} & (1) & (2) & (3) & (4) & $(5)$ \\
\hline & $\ln (\mathrm{BMI})$ & $\ln (\mathrm{BMI})$ & Obese & Overwt. & Underwt. \\
\hline Predicted to be in $1^{\text {st }}$ & -0.017 & -0.018 & 0.025 & -0.085 & 0.010 \\
\hline Grade & $(0.014)$ & $(0.014)$ & $(0.038)$ & $(0.047)$ & $(0.019)$ \\
\hline p-value & 0.232 & 0.188 & 0.515 & 0.067 & 0.606 \\
\hline Observations & 4,860 & 4,860 & 4,860 & 4,860 & 4,860 \\
\hline R-squared & 0.020 & 0.033 & 0.024 & 0.024 & 0.017 \\
\hline \multirow[t]{3}{*}{ First Stage Regression } & $(1)$ & (2) & (3) & (4) & $(5)$ \\
\hline & In $1^{\text {st }}$ & In $1^{\text {st }}$ & In $1^{\text {st }}$ & In $1^{\text {st }}$ & In $1^{\text {st }}$ \\
\hline & Grade & Grade & Grade & Grade & Grade \\
\hline Predicted to be in $1^{\text {st }}$ & 0.476 & 0.474 & 0.474 & 0.474 & 0.474 \\
\hline Grade & $(0.043)$ & $(0.043)$ & $(0.043)$ & $(0.043)$ & $(0.043)$ \\
\hline $\mathrm{p}$-value & 0.000 & 0.000 & 0.000 & 0.000 & 0.000 \\
\hline Observations & 4,860 & 4,860 & 4,860 & 4,860 & 4,860 \\
\hline R-squared & 0.670 & 0.677 & 0.677 & 0.677 & 0.677 \\
\hline Instrumental Variables & (1) & (2) & (3) & (4) & $(5)$ \\
\hline \multirow{3}{*}{ In $1^{\text {st }}$ Grade } & $\ln (\mathrm{BMI})$ & $\ln (\mathrm{BMI})$ & Obese & Overwt. & Underwt. \\
\hline & -0.036 & -0.039 & 0.052 & -0.180 & 0.021 \\
\hline & $(0.030)$ & $(0.030)$ & $(0.080)$ & $(0.100)$ & $(0.040)$ \\
\hline $\mathrm{p}$-value & 0.238 & 0.193 & 0.515 & 0.072 & 0.607 \\
\hline Observations & 4,860 & 4,860 & 4,860 & 4,860 & 4,860 \\
\hline R-squared & 0.008 & 0.020 & 0.025 & 0.006 & 0.014 \\
\hline
\end{tabular}

Notes: See notes to Table 3 for what control variables are included in each column. Standard Errors are adjusted for heterogeneity and within school correlation. The sample used for the estimates in this table is for those reporting that they do not receive a complete school lunch. 
Appendix Figure 1: Estimated Regression Discontinuity Model for $\ln (\mathrm{BMI})$

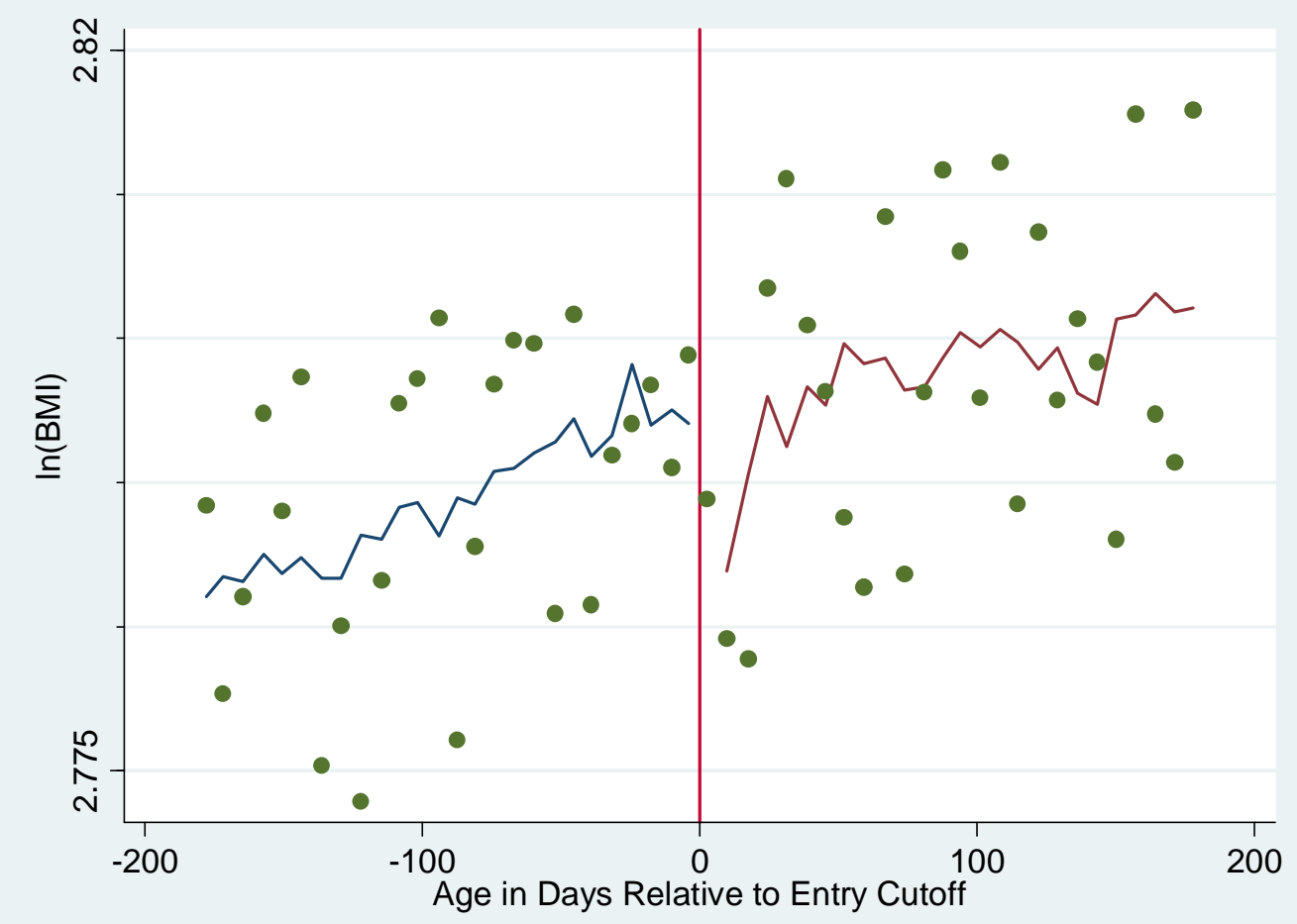

Note: Gridlines are spaced at approximately one standard error for the estimated model.

Appendix Figure 2: Estimated Regression Discontinuity Model for Probability of Overweight

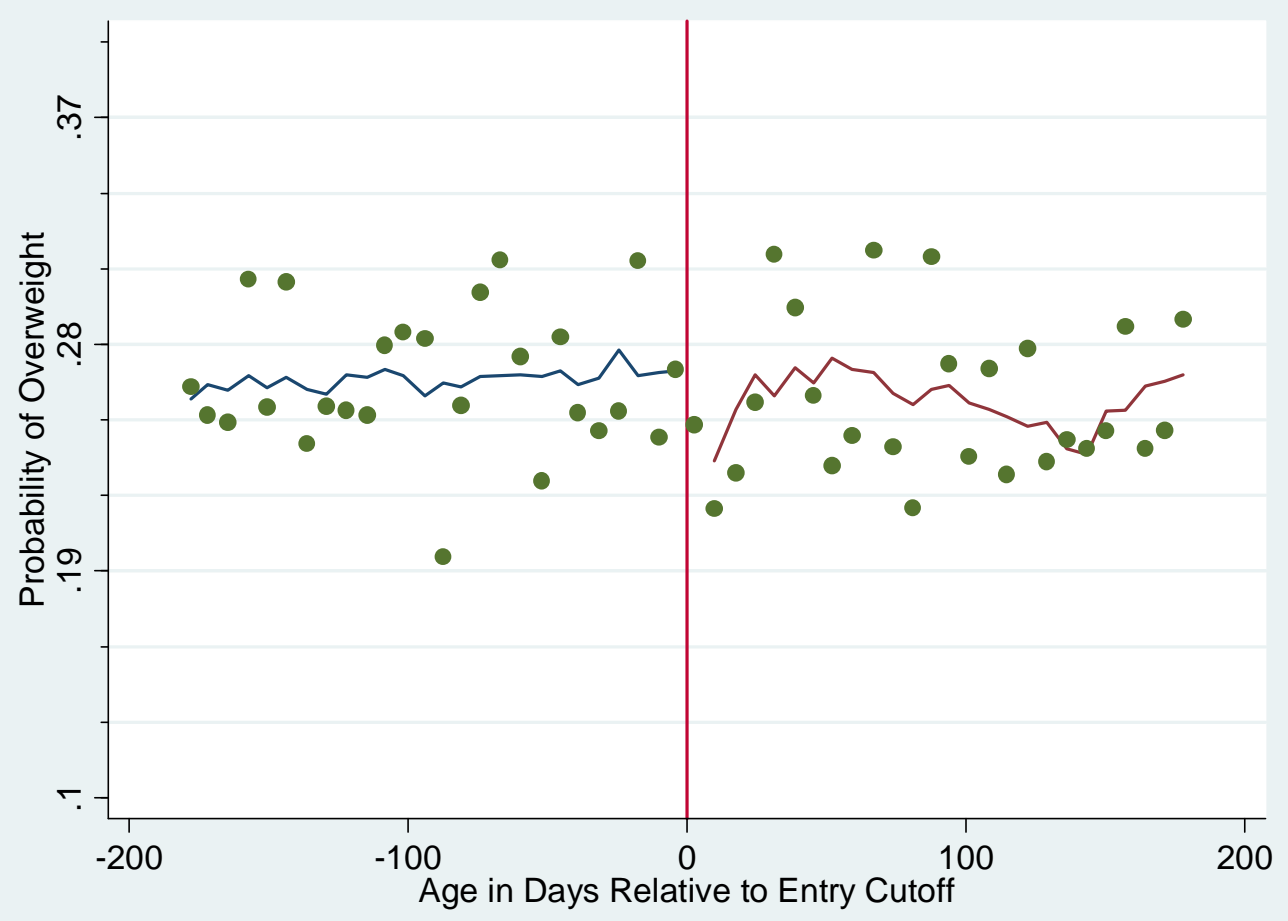

Note: Gridlines are spaced at approximately one standard error for the estimated model. 
Appendix Figure 3: Estimated Regression Discontinuity Model for Math Test Score

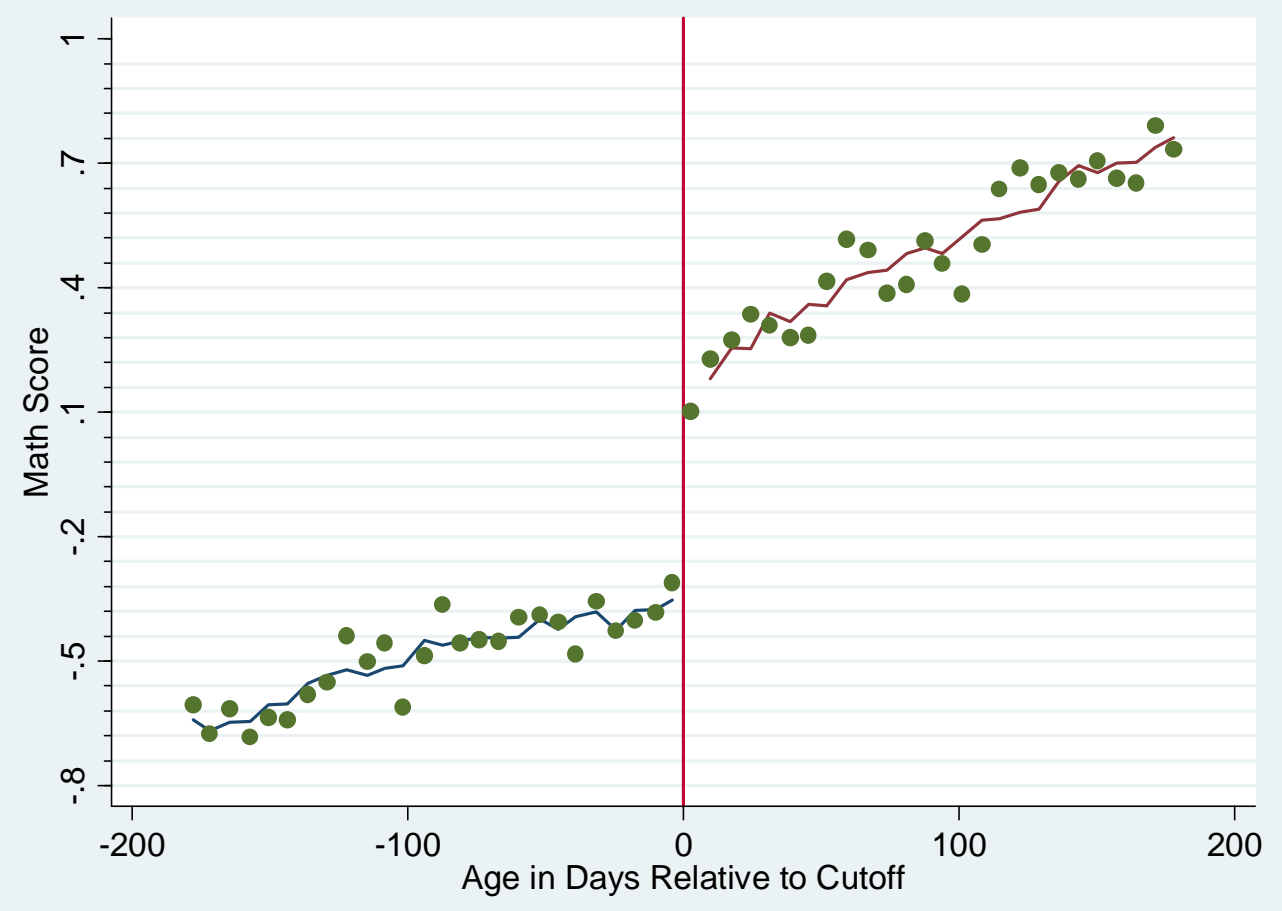

Note: Gridlines are spaced at approximately one standard error for the estimated model.

Appendix Figure 4: Estimated Regression Discontinuity Model for Probability of Overweight Students Not Eating School Lunch

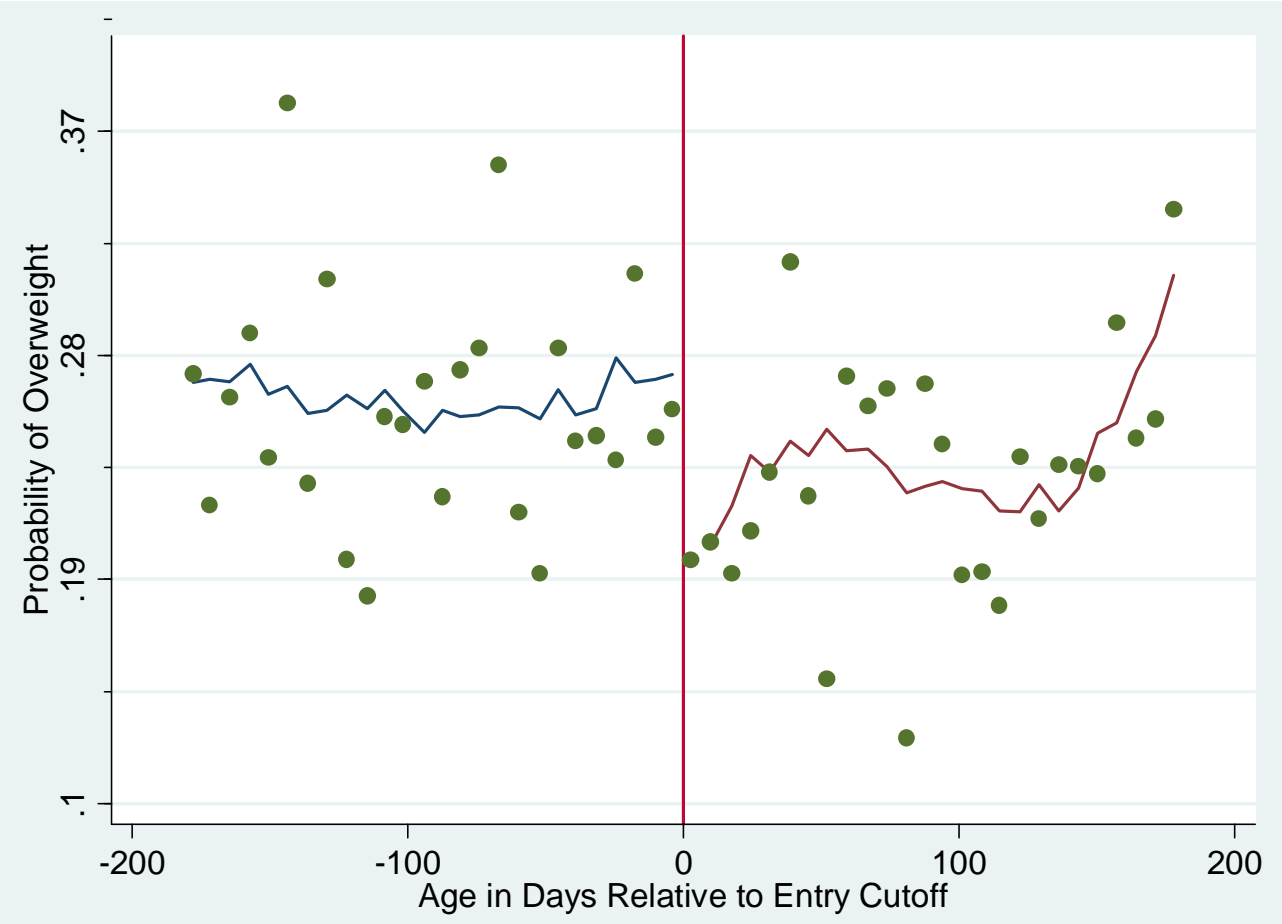

Note: Gridlines are spaced at approximately one standard error for the estimated model. 
Appendix Table 1

Summary Statistics - ECLS-K

\begin{tabular}{lccccc}
\hline \hline Variables & Obs & Mean & Std. Dev. & Min & Max \\
\hline Ln(BMI) & 12762 & 2.796 & 0.125 & 2.534 & 3.248 \\
Obese & 12762 & 0.115 & 0.319 & 0.000 & 1.000 \\
Overweight & 12762 & 0.261 & 0.439 & 0.000 & 1.000 \\
Under Weight & 12762 & 0.028 & 0.165 & 0.000 & 1.000 \\
Math Score (Standardized & 12762 & -0.001 & 0.993 & -3.828 & 2.265 \\
Across Grades) & & & & & \\
ln(birthweight) & 11920 & 4.750 & 0.216 & 2.773 & 5.389 \\
ln(height) & 12762 & 3.850 & 0.048 & 3.555 & 4.078 \\
African American & 12762 & 0.140 & 0.347 & 0.000 & 1.000 \\
Hispanic & 12762 & 0.175 & 0.380 & 0.000 & 1.000 \\
Other Race & 12762 & 0.058 & 0.233 & 0.000 & 1.000 \\
Female & 12762 & 0.487 & 0.500 & 0.000 & 1.000 \\
Mother H.S. Drop Out & 12762 & 0.178 & 0.383 & 0.000 & 1.000 \\
Mother H.S. Graduate & 12762 & 0.311 & 0.463 & 0.000 & 1.000 \\
Mother's Education & 12762 & 0.265 & 0.442 & 0.000 & 1.000 \\
Missing & & & & & \\
In 1t Grade & 12762 & 0.434 & 0.496 & 0.000 & 1.000 \\
Predicted to be in 1 $1^{\text {st }}$ Grade & 12762 & 0.500 & 0.500 & 0.000 & 1.000 \\
Age in Days Relative to the & 12762 & 0.003 & 1.030 & -1.810 & 1.810 \\
Cutoff / 100 & & & & & \\
\hline \hline
\end{tabular}


Appendix Table $2 \mathrm{a}$

Estimated Effects of School Exposure on Body Weight

Poverty Program Participants (ECLS-K)

(Clustered Standard Errors in Parentheses)

\begin{tabular}{|c|c|c|c|c|c|}
\hline OLS Regression & $(1)$ & $(2)$ & (3) & (4) & $(5)$ \\
\hline \multirow{3}{*}{ In $1^{\text {st }}$ Grade } & $\ln (\mathrm{BMI})$ & $\ln (\mathrm{BMI})$ & Obese & Overwt. & Underwt. \\
\hline & 0.0145 & 0.0128 & 0.0429 & 0.0437 & -0.0040 \\
\hline & $(0.0057)$ & $(0.0056)$ & $(0.0138)$ & $(0.0191)$ & $(0.0074)$ \\
\hline p-value & 0.0112 & 0.0231 & 0.0019 & 0.0221 & 0.5898 \\
\hline Observations & 7,473 & 7,473 & 7,473 & 7,473 & 7,473 \\
\hline R-squared & 0.0164 & 0.0267 & 0.0166 & 0.0184 & 0.0147 \\
\hline \multicolumn{6}{|l|}{ Reduced Form } \\
\hline Regression & (1) & $(2)$ & (3) & $(4)$ & $(5)$ \\
\hline \multicolumn{6}{|l|}{ Predicted to be in $1^{\text {st }}$} \\
\hline \multirow[t]{2}{*}{ Grade } & -0.0090 & -0.0103 & 0.0115 & -0.0508 & -0.0004 \\
\hline & $(0.0122)$ & $(0.0121)$ & $(0.0322)$ & $(0.0415)$ & $(0.0154)$ \\
\hline p-value & 0.4646 & 0.3925 & 0.7219 & 0.2212 & 0.9795 \\
\hline Observations & 7,473 & 7,473 & 7,473 & 7,473 & 7,473 \\
\hline R-squared & 0.0157 & 0.0262 & 0.0156 & 0.0180 & 0.0146 \\
\hline \multirow[t]{3}{*}{ First Stage Regression } & $(1)$ & (2) & (3) & $(4)$ & $(5)$ \\
\hline & In $1^{\text {st }}$ & In $1^{\text {st }}$ & In $1^{\text {st }}$ & In $1^{\text {st }}$ & In $1^{\text {st }}$ \\
\hline & Grade & Grade & Grade & Grade & Grade \\
\hline \multicolumn{6}{|l|}{ Predicted to be in $1^{\text {st }}$} \\
\hline \multirow[t]{2}{*}{ Grade } & 0.7356 & 0.7357 & 0.7357 & 0.7357 & 0.7357 \\
\hline & $(0.0290)$ & $(0.0290)$ & $(0.0290)$ & $(0.0290)$ & $(0.0290)$ \\
\hline p-value & 0.0000 & 0.0000 & 0.0000 & 0.0000 & 0.0000 \\
\hline Observations & 7,473 & 7,473 & 7,473 & 7,473 & 7,473 \\
\hline R-squared & 0.7790 & 0.7811 & 0.7811 & 0.7811 & 0.7811 \\
\hline \multicolumn{6}{|l|}{ Instrumental } \\
\hline Variables & $(1)$ & $(2)$ & (3) & $(4)$ & $(5)$ \\
\hline \multirow{3}{*}{ In $1^{\text {st }}$ Grade } & $\ln (\mathrm{BMI})$ & $\ln (\mathrm{BMI})$ & Obese & Overwt. & Underwt. \\
\hline & -0.0122 & -0.0140 & 0.0156 & -0.0690 & -0.0005 \\
\hline & $(0.0167)$ & $(0.0165)$ & $(0.0437)$ & $(0.0568)$ & $(0.0209)$ \\
\hline $\mathrm{p}$-value & 0.4662 & 0.3944 & 0.7215 & 0.2248 & 0.9795 \\
\hline Observations & 7,473 & 7,473 & 7,473 & 7,473 & 7,473 \\
\hline R-squared & 0.0137 & 0.0241 & 0.0162 & 0.0145 & 0.0147 \\
\hline
\end{tabular}

Notes: See notes to Table 3 for what control variables are included in each column. Standard Errors are adjusted for heterogeneity and within school correlation. The sample used for the estimates in this table are for those families reporting that they have participated in free or reduced price school lunch, Food Stamps, Head Start, WIC, or have been "food insecure." 
Appendix Table 2b

Estimated Effects of School Exposure on Body Weight - Poverty Program Non-Participants (Clustered Standard Errors in Parentheses)

\begin{tabular}{|c|c|c|c|c|c|}
\hline OLS Regression & (1) & (2) & (3) & (4) & (5) \\
\hline \multirow{3}{*}{ In $1^{\text {st }}$ Grade } & $\ln (\mathrm{BMI})$ & $\ln (\mathrm{BMI})$ & Obese & Overwt. & Underwt. \\
\hline & 0.0182 & 0.0181 & 0.0183 & 0.0406 & -0.0122 \\
\hline & $(0.0057)$ & $(0.0058)$ & $(0.0125)$ & $(0.0202)$ & $(0.0076)$ \\
\hline$p$-value & 0.0015 & 0.0017 & 0.1442 & 0.0452 & 0.1077 \\
\hline Observations & 5,281 & 5,281 & 5,281 & 5,281 & 5,281 \\
\hline R-squared & 0.0178 & 0.0242 & 0.0162 & 0.0160 & 0.0178 \\
\hline \multicolumn{6}{|l|}{ Reduced Form } \\
\hline \multicolumn{6}{|l|}{ Predicted to be in $1^{\text {st }}$} \\
\hline Grade & $\begin{array}{l}-0.0127 \\
(0.0132)\end{array}$ & $\begin{array}{l}-0.0129 \\
(0.0131)\end{array}$ & $\begin{array}{c}0.0034 \\
(0.0329)\end{array}$ & $\begin{array}{c}-0.0430 \\
(0.0461)\end{array}$ & $\begin{array}{l}-0.0062 \\
(0.0169)\end{array}$ \\
\hline$p$-value & 0.3370 & 0.3223 & 0.9172 & 0.3511 & 0.7126 \\
\hline Observations & 5,281 & 5,281 & 5,281 & 5,281 & 5,281 \\
\hline R-squared & 0.0161 & 0.0226 & 0.0159 & 0.0155 & 0.0174 \\
\hline \multirow[t]{3}{*}{ First Stage Regression } & (1) & (2) & (3) & (4) & (5) \\
\hline & In $1^{\text {st }}$ & In $1^{\text {st }}$ & $\operatorname{In} 1^{\text {st }}$ & $\operatorname{In} 1^{\text {st }}$ & In $1^{\text {st }}$ \\
\hline & Grade & Grade & Grade & Grade & Grade \\
\hline \multicolumn{6}{|l|}{ Predicted to be in $1^{\text {st }}$} \\
\hline Grade & $\begin{array}{c}0.4829 \\
(0.0416)\end{array}$ & $\begin{array}{c}0.4885 \\
(0.0410)\end{array}$ & $\begin{array}{c}0.4885 \\
(0.0410)\end{array}$ & $\begin{array}{c}0.4885 \\
(0.0410)\end{array}$ & $\begin{array}{c}0.4885 \\
(0.0410)\end{array}$ \\
\hline$p$-value & 0.0000 & 0.0000 & 0.0000 & 0.0000 & 0.0000 \\
\hline Observations & 5,281 & 5,281 & 5,281 & 5,281 & 5,281 \\
\hline R-squared & 0.6950 & 0.7031 & 0.7031 & 0.7031 & 0.7031 \\
\hline \multicolumn{6}{|l|}{ Instrumental } \\
\hline \multirow{3}{*}{ In $1^{\text {st }}$ Grade } & $\ln (\mathrm{BMI})$ & $\ln (\mathrm{BMI})$ & Obese & Overwt. & Underwt. \\
\hline & -0.0263 & -0.0265 & 0.0070 & -0.0881 & -0.0128 \\
\hline & $(0.0273)$ & $(0.0267)$ & $(0.0674)$ & $(0.0940)$ & $(0.0348)$ \\
\hline $\mathrm{p}$-value & 0.3352 & 0.3206 & 0.9173 & 0.3493 & 0.7133 \\
\hline Observations & 5,281 & 5,281 & 5,281 & 5,281 & 5,281 \\
\hline R-squared & 0.0066 & 0.0132 & 0.0161 & 0.0090 & 0.0178 \\
\hline
\end{tabular}

Notes: See notes to Table 3 for what control variables are included in each column. Standard Errors are adjusted for heterogeneity and within school correlation. The sample used for the estimates in this table are for those families reporting that they have not participated in free or reduced price school lunch, Food Stamps, Head Start, WIC, or have been "food insecure." 
Appendix Table 3

Estimated Effects of School Exposure on Body Weight: NLSY Children Age 5 - 6 (Clustered Standard Error in Parentheses)

\begin{tabular}{|c|c|c|c|c|}
\hline "OLS Regression & $(1)$ & (2) & (3) & $(4)$ \\
\hline \multirow{3}{*}{ Grade level } & $\operatorname{Ln}(\mathrm{BMI})$ & Ln(BMI) & Obese & Overweight \\
\hline & 0.0103 & 0.0092 & 0.0045 & 0.0032 \\
\hline & $(0.0046)$ & $(0.0046)$ & $(0.0092)$ & $(0.0118)$ \\
\hline p-value & 0.0257 & 0.0443 & 0.622 & 0.788 \\
\hline Observations & 5,536 & 5,536 & 5,536 & 5,536 \\
\hline R-squared & 0.028 & 0.077 & 0.057 & 0.060 \\
\hline \multicolumn{5}{|l|}{ Reduced Form } \\
\hline Regression & (1) & $(2)$ & (3) & (4) \\
\hline & $\operatorname{Ln}(\mathrm{BMI})$ & $\operatorname{Ln}(\mathrm{BMI})$ & Obese & Overweight \\
\hline \multirow{3}{*}{$\begin{array}{l}\text { Birth date "makes" } \\
\text { cutoff }\end{array}$} & & & & \\
\hline & 0.0126 & 0.0127 & 0.0499 & 0.0571 \\
\hline & $(0.0187)$ & $(0.0181)$ & $(0.0379)$ & $(0.0476)$ \\
\hline $\mathrm{p}$-value & 0.500 & 0.481 & 0.187 & 0.231 \\
\hline Observations & 5,536 & 5,536 & 5,536 & 5,536 \\
\hline R-squared & 0.028 & 0.076 & 0.058 & 0.060 \\
\hline \multicolumn{5}{|l|}{ First Stage } \\
\hline Regression & (1) & (2) & (3) & (4) \\
\hline \multirow{4}{*}{$\begin{array}{l}\text { Birth date "makes" } \\
\text { cutoff }\end{array}$} & Grade level & Grade level & Grade level & Grade level \\
\hline & & & & \\
\hline & 0.425 & 0.424 & 0.424 & 0.424 \\
\hline & $(0.063)$ & $(0.063)$ & $(0.063)$ & $(0.063)$ \\
\hline $\mathrm{p}$-value & 0.000 & 0.000 & 0.000 & 0.000 \\
\hline Observations & 5,536 & 5,536 & 5,536 & 5,536 \\
\hline R-squared & 0.617 & 0.622 & 0.622 & 0.622 \\
\hline \multicolumn{5}{|l|}{ Instrumental } \\
\hline \multirow{3}{*}{ Grade level } & $\mathrm{Ln}(\mathrm{BMI})$ & Ln(BMI) & Obese & Overweight \\
\hline & 0.0296 & 0.0300 & 0.118 & 0.134 \\
\hline & $(0.0441)$ & $(0.0427)$ & $(0.0910)$ & $(0.114)$ \\
\hline p-value & 0.502 & 0.482 & 0.196 & 0.237 \\
\hline Observations & 5,536 & 5,536 & 5,536 & 5,536 \\
\hline R-squared & 0.025 & 0.073 & 0.031 & 0.038 \\
\hline
\end{tabular}

Notes: Standard errors are adjusted for heterogeneity and within family correlation. "Grade level" is the grade reported, converted to expected grade in the Fall of a given year. "Birthdate 'makes' cutoff" means the individual was born on or before the date by which the individual has to turn 5 in order to be eligible to start kindergarten in a given cohort in a given state. Column 1 controls for a cubic in days from the individuals' birth days to the school starting age cutoff for the individuals' states of residence when they were 5 years old. Interactions between these age variables and a dummy variable indicating the individual "made the cutoff" are also included. Ten year dummies are included. Twenty-one dummy variables are included for each cutoff date used by states. Columns (2)-(4) add controls for race/ethnicity, sex, mothers' characteristics: African American, Hispanic Female, mother H.S. drop out, Mother completed H.S., Mother has some college, Mother graduated college (additional education is the omitted category), mother is missing education information, mother's Armed Forces Qualifying Test (AFQT) score, Mother's AFQT information is missing, Mother's $\ln (\mathrm{BMI})$, Mother's BMI information is missing, mother's age at the child's birth. 
Appendix Table 4

Estimated Effects of School Exposure on Body Weight: NLSY Children Age 5-10 (Clustered Standard Errors in Parentheses)

\begin{tabular}{|c|c|c|c|c|}
\hline OLS Regression & (1) & $(2)$ & (3) & (4) \\
\hline \multirow{3}{*}{ Grade level } & Ln(BMI) & Ln(BMI) & Obese & Overweight \\
\hline & 0.0120 & 0.0135 & 0.00491 & 0.0129 \\
\hline & $(0.0033)$ & $(0.0031)$ & $(0.0059)$ & $(0.0072)$ \\
\hline $\mathrm{p}$-value & 0.000234 & $1.71 \mathrm{e}-05$ & 0.402 & 0.0749 \\
\hline Observations & 15,929 & 15,929 & 15,929 & 15,929 \\
\hline R-squared & 0.123 & 0.179 & 0.060 & 0.071 \\
\hline \multicolumn{5}{|l|}{ Reduced Form } \\
\hline \multirow[t]{2}{*}{ Regression } & (1) & (2) & (3) & (4) \\
\hline & $\operatorname{Ln}(\mathrm{BMI})$ & $\operatorname{Ln}(\mathrm{BMI})$ & Obese & Overweight \\
\hline \multicolumn{5}{|l|}{ Birth date } \\
\hline \multirow[t]{2}{*}{ "makes" cutoff } & 0.00738 & 0.00717 & 0.0372 & 0.0352 \\
\hline & $(0.0178)$ & $(0.0169)$ & $(0.0315)$ & $(0.0379)$ \\
\hline p-value & 0.679 & 0.672 & 0.238 & 0.352 \\
\hline Observations & 15,929 & 15,929 & 15,929 & 15,929 \\
\hline R-squared & 0.122 & 0.178 & 0.061 & 0.070 \\
\hline \multicolumn{5}{|l|}{ First Stage } \\
\hline \multirow[t]{2}{*}{ Regression } & (1) & $(2)$ & (3) & (4) \\
\hline & Grade level & Grade level & Grade level & Grade level \\
\hline \multicolumn{5}{|l|}{ Birth date } \\
\hline \multirow[t]{2}{*}{ "makes" cutoff } & 0.451 & 0.446 & 0.446 & 0.446 \\
\hline & $(0.053)$ & $(0.052)$ & $(0.052)$ & $(0.052)$ \\
\hline p-value & 0.000 & 0.000 & 0.000 & 0.000 \\
\hline Observations & 15,929 & 15,929 & 15,929 & 15,929 \\
\hline R-squared & 0.902 & 0.903 & 0.903 & 0.903 \\
\hline \multicolumn{5}{|l|}{ Instrumental } \\
\hline Variables & (1) & (2) & (3) & (4) \\
\hline \multirow{3}{*}{ Grade level } & $\mathrm{Ln}(\mathrm{BMI})$ & $\mathrm{Ln}(\mathrm{BMI})$ & Obese & Overweight \\
\hline & 0.0163 & 0.0161 & 0.0833 & 0.0790 \\
\hline & $(0.0395)$ & $(0.0380)$ & $(0.0713)$ & $(0.0852)$ \\
\hline p-value & 0.679 & 0.672 & 0.243 & 0.354 \\
\hline Observations & 15,929 & 15,929 & 15,929 & 15,929 \\
\hline R-squared & 0.123 & 0.179 & 0.046 & 0.064 \\
\hline
\end{tabular}

Notes: See notes to Appendix Table 3. 